Original article

\title{
Sensitivity of conventional radiographs and cone-beam computed tomography in detecting the remaining root-canal filling material
}

\author{
Steffi Baxter ${ }^{1)}$, Christian Schöler ${ }^{1)}$, Christian Dullin²), and Michael Hülsmann ${ }^{1)}$ \\ 1) Department of Preventive Dentistry, Periodontology and Cariology, University of Göttingen, Göttingen, Germany \\ ${ }^{2)}$ Department of Diagnostic Radiology, University of Göttingen, Göttingen, Germany
}

(Received March 7, 2019; Accepted August 30, 2019)

\begin{abstract}
This study aimed to compare the sensitivity of radiographs and flat-panel volume-computed tomography (fpVCT) in detecting the remaining root-canal filling material. Thirty-two root canals in extracted human mandibular molars were prepared and obturated with gutta-percha and sealer. The filling material was removed, and the teeth were split longitudinally. Radiographs and fpVCT scans were obtained and digitized. Virtual images were developed using reconstruction software and then superimposed, and the remaining filling material was outlined. Direct observation of the split root halves using flatbed scans served as a control. The presence and extension of the remaining filling material were evaluated. Statistical analysis was conducted using chi-squared test $(P<0.05)$. A total of 116 remnants were detected in the flatbed scans, 81 in the fpVCT scans, and 90 in the radiographs, with no significant difference between the radiograph (78\%) and fpVCT $(70 \%)$ results $(P=0.18)$. In the fpVCT scans, $42 \%$ of the remnants exhibited the same dimensions as the control, whereas $27 \%$ appeared larger and 30\% appeared smaller. In the radiographs, the dimensions of the remnants were identical to the control in $64 \%$ of cases, smaller in $29 \%$, and larger in $7 \%$. FpVCT did not exhibit better performance than dental radiographs in detecting the remaining root-canal-filling material: the extension of remnants was indicated correctly in the fpVCT in fewer than $50 \%$ of the samples.
\end{abstract}

Keywords; dental radiograph, endodontic retreatment, flat-panel volumecomputed tomography, gutta-percha remnants

\section{Introduction}

Orthograde retreatment represents an important treatment option in cases of primary endodontic treatment failure. Complete removal of root-canal filling material is essential to permit adequate re-preparation, disinfection, and re-obturation of the root-canal system. Nevertheless, it has been demonstrated in numerous studies that it is difficult, if not impossible, to achieve complete removal of gutta-percha and sealer [1-5].

In experimental studies, roots can be split longitudinally and observed under a microscope to control complete removal. Clinically, the use of a dental operating microscope can be helpful to detect remnants of filling material, but this is limited to the straight part of the root canal in curved roots $[2,6,7]$. Alternative techniques to control the removal of the filling material in vivo include dental radiography, or simple use of tactile sense and visual control of instruments.

In contemporary endodontics, cone-beam computed tomography has become an important diagnostic tool. In contrast to dental radiographs, this technique generates three-dimensional images. In numerous studies and case reports, cone-beam computed tomography has been shown to be helpful in visualizing additional root canals [8], vertical root fractures $[9,10]$, size and location of periapical lesions $[11,12]$, external or internal resorptions [13], voids inside root fillings [14,15], and details of root-canal morphology $[12,16]$.

Correspondence to Dr. Steffi Baxter, Department of Preventive Dentistry, Periodontology and Cariology, University of Göttingen, Robert-Koch-Str. 40, Göttingen 37075, Germany

Fax: +49-551-3922037 Email: steffi.baxter@med.uni-goettingen.de

J-STAGE Advance Publication: June 4, 2020

Color figures can be viewed in the online issue at J-STAGE.

doi.org/10.2334/josnusd.19-0100

DN/JST.JSTAGE/josnusd/19-0100
Flat-panel volume-computed tomography (fpVCT) allows for thorough, three-dimensional exploration of dental arches or human heads at a high resolution $[17,18]$, which is superior to conventional CT systems [19-22]. It has already been shown that fpVCT is a suitable diagnostic tool for the detection of anatomical structures, such as lateral canals and pulp stones [22]

On this basis, it could be assumed that fpVCT might also exhibit superior performance in detecting residual root-canal filling material in endodontic retreatment procedures compared with dental radiographs.

The aim of this experimental study was to determine and compare the sensitivity of conventional dental radiographs and fpVCT in detecting the remaining root-canal filling material in extracted human teeth.

\section{Materials and Methods}

This study was approved by the ethics committee of the University of Göttingen (DOK_155_2016).

\section{Sample preparation}

Thirty-two human mandibular molars, which had been extracted for reasons not related to this study, were collected. After extraction, the teeth were stored in $0.1 \%$ thymol at room temperature. In each tooth, one root canal was prepared and obturated with AH Plus (Dentsply DeTrey, Konstanz, Germany) and gutta-percha (VDW, Munich, Germany). The root-canal filling material was removed 6 weeks after the setting of the sealer, using nickel-titanium instruments. When removal was considered to be complete, with no further filling material visible on the instruments, the teeth were split longitudinally using a cutting blade that did not penetrate the root canal. The grooved roots were finally separated using a spatula (Aesculap by Braun, Melsungen, Germany).

The samples were dried, and the root halves were embedded into blocks of transparent polyether cast resin material (EFCO, Rohrbach, Germany) measuring $30 \times 40 \mathrm{~mm}$ wide and $10 \mathrm{~mm}$ thick. For a three-dimensional orientation during image processing, and to allow exact superimposition of different images, three different radio-opaque reference elements were embedded into the resin samples. These metallic elements were positioned as far from the tooth halves as possible to permit unhindered beam projection and to prevent any beam-hardening effects. The resin samples were polished $24 \mathrm{~h}$ after sample preparation, when the curing process at room temperature was finished, removing approximately $0.1 \mathrm{~mm}$ of the uncured surface layer.

\section{Image preparation and data interpretation}

A $30 \times 40 \mathrm{~mm}$ dental radiograph (Dentus M2, AGFA-Gevaert, Mortsel, Belgium; Heliodent MD, Sirona, Bensheim, Germany) and an fpVCT image (General Electric Global Research Centers, Niskayuna, NY, USA) were taken of each sample. A resin board was positioned within the field of view while obtaining the fpVCT images. The tube voltage was set at 80 $\mathrm{kV}$ and the tube current at $100 \mathrm{~mA}$. The longitudinal axis of each sample was positioned vertical to the course of the beam. Great care was taken to ensure that all images were captured in identical projection to prevent perspective distortion in both the radiographs and fpVCT images. The fpVCT scans were converted into two-dimensional images.

Flatbed scans with an optical resolution of 1,600 $\times 3,200$ dpi were obtained of each sample to serve as controls. A molding tool was used to ensure the ideal positioning of each sample. All images were saved in 


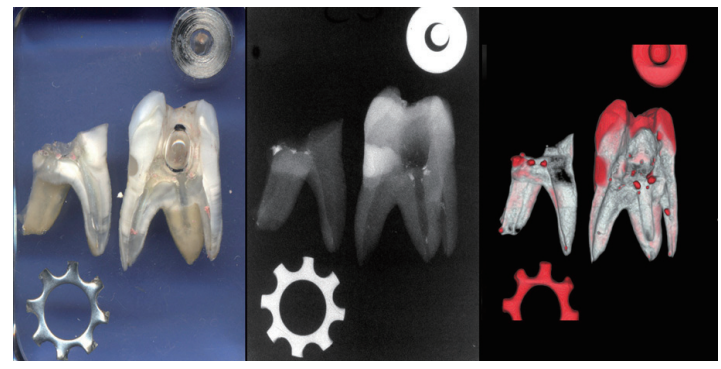

Fig. 1 Example of comparison of direct view using the flatbed scan, radiograph, and fpVCT images of a tooth with gutta-percha remnants. Bar length is $2.7 \mathrm{~mm}$.

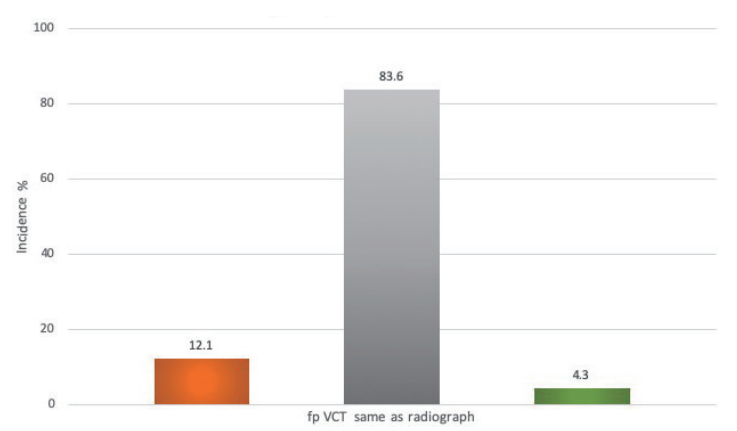

Fig. 3 Agreement between radiograph and fpVCT in the detection of gutta-percha remnants. For most of the remnants $(84 \%)$, no difference is observed between the two methods. In $12 \%$ of the samples, gutta-percha remnants were detected only in the radiographs, whereas in $4 \%$ of the samples, remnants were only detected in the fpVCT scans. The total number of remnants observed in the flatbed scans was 116

Adobe Photoshop CS (Adobe Systems, San Jose, CA, USA).

For image evaluation, the control images, radiographs, and fpVCT images were straightened using the reference elements, resulting in identical dimensions for all three types of image (Fig. 1). All gutta-percha and sealer remnants were outlined and coded with different colors, applied independently in each image. The remnants in the fpVCT images were marked with red, whereas the remnants in the radiographs were marked with blue and the control images with green (Fig. 2). Adobe Photoshop CS was used to superimpose the different images onto the control image, and optimal congruence was achieved by superimposition of the reference objects.

The observer analyzed whether root-canal filling remnants could be detected in the control image, radiograph, and fpVCT image. A score of 1 was recorded when filling material was detectable, and a score of 0 was recorded when no filling material was visible. True-positive, true-negative, false-positive, and false-negative findings were noted for each sample. The sensitivity levels of the radiographs and fpVCT scans for the detection of remnants were calculated.

To evaluate the extension of the remaining root-canal-filling material, the extension of remnants in each radiograph and fpVCT scan was correlated with that observed in the corresponding control image (larger than control $=+1$; same size as control $=0$; smaller than control $=-1$ ).

\section{Statistical evaluation}

Statistical evaluation was conducted using chi-squared test, with $P<0.05$.

\section{Results}

\section{Detection of root-canal-filling material}

A total of 116 remnants of filling material were detected in the flatbed scans: 90 of these were detected in the radiographs and 81 in the fpVCT images. The sensitivity level for the detection of the remaining root-canal filling material was 0.70 for the fpVCT images and 0.78 for the radiographs; i.e., the remaining material was correctly identified in $70 \%$ and $78 \%$ of the images, respectively. False-negative results were returned in $29 \%(n=34)$

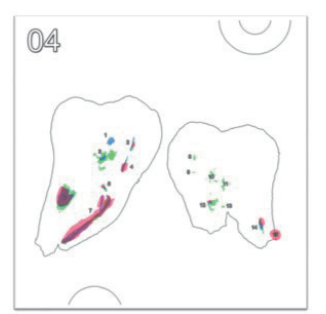

Fig. 2 Example of a superimposition of the three types of scans and images. Remnants are colored as follows: green in the control, blue in the radiograph, and red in the $\mathrm{fpVCT}$. Numbers indicate numbering of remnants.

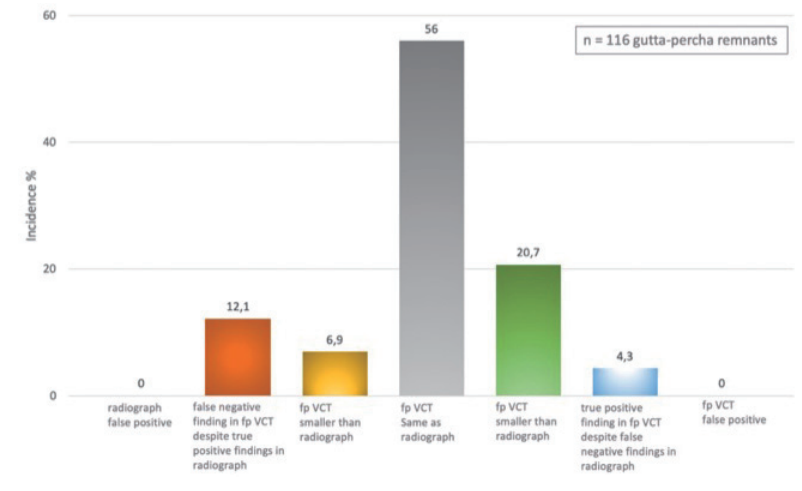

Fig. 4 Agreement between radiograph and fpVCT scan regarding the two-dimensional extension of gutta-percha remnants. In $56 \%$ of the remnants, equivalent sizes of extension were shown by radiographs and fpVCT, whereas $20.7 \%$ were seen as larger and $6.9 \%$ smaller in fpVCT than in radiographs. In $12.1 \%$ of samples, false-negative detection occurred in fpVCT, and true-positive detection occurred in only $4.3 \%$ of the samples. There were no false-positive findings. The total number of remnants observed in the flatbed scans was 116 .

and $22 \%(n=25)$ of the specimens, respectively. The differences between the radiograph and fpVCT findings were not statistically significant $(P>$ 0.05 ), and neither technique returned any false-positive results. Thus, both radiographs and fpVCT scans have a positive predictive value of $100 \%$.

A comparison of the radiograph and fpVCT results shows no statistically significant difference $(P=0.18)$ between these image-guided techniques in $84 \%$ of cases. The fpVCT findings were more accurate in only $4 \%$ of cases, whereas the radiographs were more accurate in $12 \%$ of cases (Fig. 3).

\section{Extension of root-canal-filling material}

In the majority of cases (64\%), conventional radiographs revealed an extension of residual filling material equivalent to or smaller $(29 \%)$ than that observed in the flatbed scans, and a larger extension was only observed in a small proportion of cases (7\%). In comparison with the control images, $43 \%$ of the fpVCT scans revealed an equivalent amount of filling material, whereas $27 \%$ revealed smaller remnants, and 30\% revealed larger remnants. The difference in accuracy of observing extension of the remaining filling material between the radiographs and the fpVCT scans was significant $(P<0.001)$, with the radiograph showing superior performance.

A comparison between the radiographs and the fpVCT scans shows identical results in $56 \%$ of the specimens. In the fpVCT scans, the filling material remnants appeared larger in $20.7 \%$ of samples and smaller in $6.9 \%$ of samples compared with those in the radiographs. In $12.1 \%$ of samples, the fpVCT scans did not indicate the presence of gutta-percha even though it could be detected in the corresponding radiographs. On the other hand, $4.3 \%$ of cases of gutta-percha remnants detected in fpVCT scans were not observed in the corresponding radiographs (Fig. 4).

\section{Discussion}

The success rate of endodontic retreatment ranges from $40 \%$ to $100 \%$ [23]. The removal of gutta-percha and sealer is an important prerequisite for a high success rate, as otherwise, residual bacteria or necrotic tissue may sustain periapical inflammation or persistent pain. Several devices and 
techniques are available to ensure complete removal of gutta-percha remnants, including radiographs, microscopes, and direct observation [1-5].

To the best of the authors' knowledge, this is the first study comparing the precision of conventional radiography, fpVCT, and direct observation for endodontic purposes. Contrary to expectations, two-dimensional fpVCT images do not exhibit superior performance in detecting residual root-canal filling material compared with dental radiographs. Significant differences were observed between the effectiveness of the two techniques for examining the extension of residual filling material. The three-dimensional images provided by the fpVCT technique allow a three-dimensional analysis of any remnants, but it has not been shown to be important or helpful from a clinical view. Additionally, there is as yet no evidence that the size of a filling remnant has any impact on the success of the treatment. In some cases, it might be helpful to know the details of the exact location of the remnant, for example, whether it is located on the buccal or the lingual wall of the root canal, for which a three-dimensional view would be required.

Many studies have been conducted concerning the efficacy of different techniques in removing root-canal filling material, with some suggesting that, irrespective of the removal technique, complete removal of the filling material cannot be achieved under any circumstances [24-28]. Researchers have examined the detectability of residual filling material using a range of techniques, including dental radiographs [27,29,30], micro CT [31-33], computed-volume tomography, dental operating microscopes, and clearing techniques [1,2,34-36]. In the current study, flatbed scans were used as control images. The fpVCT technique has been employed for endodontic purposes in three previous studies by Hannig et al. [37,38] and Heidrich et al. [22], who concluded that root-canal anatomy and vertical root fractures could both be detected reasonably well by fpVCT, due to the high resolution and the advantages of effective three-dimensional imaging. In the present study, two-dimensional images were compared with twodimensional radiographs. The results reveal that small volumes of filling material residue are detectable by neither fpVCT scans nor radiographs, probably due to low radiographic contrast in remnants with low thickness. Therefore, fpVCT is not superior to radiographs for the detection of rootcanal filling material. The findings of this study indicate that the sensitivity levels of both techniques range from $70 \%$ to $78 \%$, which is similar to the results reported by Schirrmeister et al. [1]. Compared with radiographs, the fpVCT technique presents some major disadvantages, including high radiation exposure, time-consuming processes, and high costs, leading to the conclusion that radiographs should be favored for this diagnostic purpose.

Only one study, by Schirrmeister et al. [2], has previously compared two different techniques for the detection of residual root-canal filling material, whereas other studies have explored the efficacy of different techniques and/or solvents in removing such material. Schirrmeister et al. [34] examined the detectability of residual Epiphany and gutta-percha after root-canal retreatment using a dental operating microscope and dental radiographs in straight root canals. The teeth were cleared to evaluate the residual material. The results of their study revealed significantly smaller areas of residual gutta-percha and Epiphany using the radiographs compared with the dental microscope, especially for the gutta-percha group. Use of a dental microscope is therefore helpful and essential in endodontics; however, it is less useful in curved root canals for the detection of residual filling material in areas located apically to the curve.

In the present study, gutta-percha remnants appeared smaller in the radiographs compared with the control, whereas larger amounts of guttapercha were observed in the fpVCT scans. Similar results were observed by Betti and Bramante [26].

One reason why gutta-percha is less detectable by radiography may be the poor radio-opacity of thin layers of sealer and gutta-percha, with the remaining filling material appearing larger in $\mathrm{fpVCT}$ scans due to a larger scattering around radio-opaque material. In interpreting the results of the present study, it must be noted that only root halves were evaluated. If complete, un-sectioned roots had been analyzed, the layer of surrounding dentin and cementum would have been thicker.

Further research should be conducted using different devices to perform computed-volume tomography for comparison with dental radiographs.

It can be concluded that, under the limitations of the present study, twodimensional images generated by fpVCT are not more effective than dental radiographs for detecting the remaining root-canal filling material.

This research did not receive any specific grants from funding agencies in the public, commercial, or not-for-profit sectors.

\section{Acknowledgments}

The authors acknowledge support by Open Access Publication Funds of the University of Göttingen.

\section{Conflict of interest}

None.

\section{References}

1. Schirrmeister JF, Hermanns P, Meyer KM, Goetz F, Hellwig E (2006) Detectability of residual Epiphany and gutta-percha after root canal retreatment using a dental operating microscope and radiographs-an ex vivo study. Int Endod J 39, 558-565.

2. Schirrmeister JF, Meyer KM, Hermanns P, Altenburger MJ, Wrbas KT (2006) Effectiveness of hand and rotary instrumentation for removing a new synthetic polymer-based root canal obturation material (Epiphany) during retreatment. Int Endod J 39, 150-156.

3. Somma F, Cammarota G, Plotino G, Grande NM, Pameijer CH (2008) The effectiveness of manual and mechanical instrumentation for the retreatment of three different root canal filling materials. J Endod 34,466-469.

4. Monguilhott Crozeta B, Damião de Sousa-Neto M, Bianchi Leoni G, Francisco MazziChaves J, Terezinha Corrêa Silva-Sousa Y, Baratto-Filho F (2016) A micro-computed tomography assessment of the efficacy of rotary and reciprocating techniques for filling material removal in root canal retreatment. Clin Oral Investig 20, 2235-2240.

5. Silva EJNL, Belladonna FG, Zuolo AS, Rodrigues E, Ehrhardt IC, Souza EM et al. (2018) Effectiveness of XP-endo Finisher and XP-endo Finisher R in removing root filling remnants: a micro-CT study. Int Endod J 51, 86-91.

6. Wong R (2004) Conventional endodontic failure and retreatment. Dent Clin North Am 48, 265-289

7. Rached-Júnior FA, Sousa-Neto MD, Bruniera JF, Duarte MA, Silva-Sousa YT (2014) Confocal microscopy assessment of filling material remaining on root canal walls after retreatment. Int Endod J 47, 264-270.

8. Abuabara A, Baratto-Filho F, Aguiar Anele J, Leonardi DP, Sousa-Neto MD (2013) Efficacy of clinical and radiological methods to identify second mesiobuccal canals in maxillary first molars. Acta Odontol Scand 71, 205-209.

9. Patel S, Brady E, Wilson R, Brown J, Mannocci F (2013) The detection of vertical roo fractures in root filled teeth with periapical radiographs and CBCT scans. Int Endod J 46, $1140-1152$.

10. Brady E, Mannocci F, Brown J, Wilson R, Patel S (2014) A comparison of cone beam computed tomography and periapical radiography for the detection of vertical root fractures in nonendodontically treated teeth. Int Endod J 47, 735-746.

11. Venskutonis T, Daugela P, Strazdas M, Juodzbalys G (2014) Accuracy of digital radiography and cone beam computed tomography on periapical radiolucency detection in endodontically treated teeth. J Oral Maxillofac Res 5, e1.

12. Davies A, Mannocci F, Mitchell P, Andiappan M, Patel S (2015) The detection of periapical pathoses in root filled teeth using single and parallax periapical radiographs versus cone beam computed tomography — a clinical study. Int Endod J 48, 582-592.

13. Patel S, Horner K (2009) The use of cone beam computed tomography in endodontics. Int Endod J 42, 755-756.

14. Kositbowornchai S, Hanwachirapong D, Somsopon R, Pirmsinthavee S, Sooksuntisakoonchai N (2006) Ex vivo comparison of digital images with conventional radiographs for detection of simulated voids in root canal filling material. Int Endod J 39, 287-292.

15. Huybrechts B, Bud M, Bergmans L, Lambrechts P, Jacobs R (2009) Void detection in root fillings using intraoral analogue, intraoral digital and cone beam CT images. Int Endod J $42,675-685$.

16. Blattner TC, George N, Lee CC, Kumar V, Yelton CD (2010) Efficacy of cone-beam computed tomography as a modality to accurately identify the presence of second mesiobuccal canals in maxillary first and second molars: a pilot study. J Endod 36, 867-870.

17. Schaaf H, Wahab-Göthe T, Kerkmann H, Streckbein P, Obert M, Pons-Kuehnemann J et al. (2017) Comparison between flat-panel volume computed tomography and histologic assessments of bone invasion of maxillofacial tumors: utility of an instantaneous radiologic diagnostic tool. Oral Surg Oral Med Oral Pathol Oral Radiol 124, 91-198.

18. Hänsel NH, Schubert GA, Scholz B, Nikoubashman O, Othman AE, Wiesmann M et al (2018) Implant-specific follow-up imaging of treated intracranial aneurysms: TOF-MRA vs. metal artifact reduced intravenous flat panel computed tomography angiography (FPCTA). Clin Radiol 73, 218.e9-218.e15.

19. Ning R, Chen B, Yu R, Conover D, Tang X, Ning Y (2000) Flat panel detector-based conebeam volume CT angiography imaging: system evaluation. IEEE Trans Med Imaging 19, 949-963.

20. Ning R, Tang X, Conover D, Yu R (2003) Flat panel detector-based cone beam computed tomography with a circle-plus-two-arcs data acquisition orbit: preliminary phantom study. Med Phys 30, 1694-1705.

21. Kiessling F, Greschus S, Lichy MP, Bock M, Fink C, Vosseler S et al. (2004) Volumetric computed tomography (VCT): a new technology for noninvasive, high-resolution monitoring of tumor angiogenesis. Nat Med 10, 1133-1138.

22. Heidrich G, Hassepass F, Dullin C, Attin T, Grabbe E, Hannig C (2005) [Non-destructive, preclinical evaluation of root canal anatomy of human teeth with flat-panel detector volume CT (FD-VCT)]. Rofo 177, 1683-1690.

23. Paik S, Sechrist C, Torabinejad M (2004) Levels of evidence for the outcome of endodontic retreatment. J Endod 30, 745-750.

24. Imura N, Kato AS, Hata GI, Uemura M, Toda T, Weine F (2000) A comparison of the relative efficacies of four hand and rotary instrumentation techniques during endodontic retreatment. Int Endod J 33, 361-366.

25. Sae-Lim V, Rajamanickam I, Lim BK, Lee HL (2000) Effectiveness of ProFile .04 taper rotary instruments in endodontic retreatment. J Endod 26, 100-104. 
26. Betti LV, Bramante CM (2001) Quantec SC rotary instruments versus hand files for guttapercha removal in root canal retreatment. Int Endod J 34, 514-519.

27. Hülsmann M, Bluhm V (2004) Efficacy, cleaning ability and safety of different rotary NiTi instruments in root canal retreatment. Int Endod J 37, 468-476.

28. Masiero AV, Barletta FB (2005) Effectiveness of different techniques for removing guttapercha during retreatment. Int Endod J 38, 2-7.

29. Ferreira JJ, Rhodes JS, Ford TR (2001) The efficacy of gutta-percha removal using ProFiles. Int Endod J 34, 267-274.

30. Gergi R, Sabbagh C (2007) Effectiveness of two nickel-titanium rotary instruments and a hand file for removing gutta-percha in severely curved root canals during retreatment: an ex vivo study. Int Endod J 40, 532-537.

31. Barletta FB, Rahde Nde M, Limongi O, Moura AA, Zanesco C, Mazocatto G (2007) In vitro comparative analysis of 2 mechanical techniques for removing gutta-percha during retreatment. J Can Dent Assoc 73, 65.

32. Hammad M, Qualtrough A, Silikas N (2008) Three-dimensional evaluation of effectiveness of hand and rotary instrumentation for retreatment of canals filled with different materials. J Endod 34, 1370-1373.
33. Roggendorf MJ, Legner M, Ebert J, Fillery E, Frankenberger R, Friedman S (2010) MicroCT evaluation of residual material in canals filled with Activ GP or GuttaFlow following removal with NiTi instruments. Int Endod J 43, 200-209.

34. Schirrmeister JF, Wrbas KT, Meyer KM, Altenburger MJ, Hellwig E (2006) Efficacy of different rotary instruments for gutta-percha removal in root canal retreatment. J Endod 32, 469-472.

35. Schirrmeister JF, Wrbas KT, Schneider FH, Altenburger MJ, Hellwig E (2006) Effectiveness of a hand file and three nickel-titanium rotary instruments for removing gutta-percha in curved root canals during retreatment. Oral Surg Oral Med Oral Pathol Oral Radiol Endod 101, 542-547.

36. Gu LS, Ling JQ, Wei X, Huang XY (2008) Efficacy of ProTaper Universal rotary retreatment system for gutta-percha removal from root canals. Int Endod J 41, 288-295.

37. Hannig C, Dullin C, Hülsmann M, Heidrich G (2005) Three-dimensional, non-destructive visualization of vertical root fractures using flat panel volume detector computer tomography: an ex vivo in vitro case report. Int Endod J 38, 904-913.

38. Hannig C, Krieger E, Dullin C, Merten HA, Attin T, Grabbe E et al. (2006) Volumetry of human molars with flat panel-based volume CT in vitro. Clin Oral Investig 10, 253-257. 